Proceeding Paper

\title{
Adaptive Management in Relict Mediterranean Forests. Thinning Enhances Long-Term Growth but Short-Term Resilience to Drought in Abies pinsapo ${ }^{+}$
}

\author{
Pablo Casas-Gómez ${ }^{1}$, Raúl Sánchez-Salguero ${ }^{1}$, Víctor Lechuga ${ }^{2}$, Benjamín Viñegla ${ }^{2}$, José Ignacio Seco Gordillo ${ }^{1}$, \\ José Antonio Carreira ${ }^{2}$ and Juan Carlos Linares ${ }^{1, *}$
}

Citation: Casas-Gómez, P.;

Sánchez-Salguero, R.; Lechuga, V.;

Viñegla, B.; Gordillo, J.I.S.; Carreira,

J.A.; Linares, J.C. Adaptive

Management in Relict

Mediterranean Forests. Thinning Enhances Long-Term Growth but Short-Term Resilience to Drought in Abies pinsapo. Environ. Sci. Proc. 2021, 3, 24. https://doi.org/10.3390/IECF 2020-07880

Academic Editors: Angela Lo Monaco, Cate Macinnis-Ng and Om P. Rajora

Published: 11 November 2020

Publisher's Note: MDPI stays neutral with regard to jurisdictional claims in published maps and institutional affiliations.

\section{Copyright: $₫ 2020$ by the authors.} Licensee MDPI, Basel, Switzerland. This article is an open access article distributed under the terms and conditions of the Creative Commons Attribution (CC BY) license (http://creativecommons.org/licenses /by/4.0/).
1 Departamento de Sistemas Físicos, Químicos y Naturales, Universidad Pablo de Olavide. Ctra. Utrera km. 1, 41002 Sevilla, Spain; casasgomezpablo@gmail.com (P.C.-G.); rsanchez@upo.es (R.S.-S.); jisecgor@upo.es (J.I.S.G.)

2 Departamento de Biología Animal, Biología Vegetal y Ecología, Universidad de Jaén, Ed. B3, Paraje las Lagunillas s/n, 23071 Jaén, Spain; vlechuga@ujaen.es (V.L.); bvinegla@ujaen.es (B.V.); jafuente@ujaen.es (J.A.C.)

* Correspondence: jclincal@upo.es

† Presented at the 1st International Electronic Conference on Forests - Forests for a Better Future: Sustainability, Innovation, Interdisciplinarity, 15-30 November 2020; Available online: https://iecf2020.sciforum.net.

\begin{abstract}
Current climate change in the Mediterranean basin is associated to increasing frequency and intensity of droughts. This climate dryness entails a serious impact on drought-sensitive forests, several of them considered as hot spots of biodiversity. Adaptive management, as experimental thinning for stand structural diversity enhancement, may increase tree-level resources availability. However, the long-term stand-level effectiveness of this approach at sustaining forest ecosystem functioning remains uncertain. Here, we attempt to place experimental thinning in a climate change adaptation context, using as experimental system the drought-sensitive fir Abies pinsapo. We conducted a long-term study (2004-2019), focused on tree basal area increment (BAI) and quantified to what extent thinning treatments improved drought resistance, recovery and resilience to drought in the remaining trees. The results support a post-thinning (after 2004) BAI increase in thinned stands $(+104 \%$ if $30 \%$ thinning of basal area was applied; $+141 \%$ for $60 \%$ thinning) compared to controls $(+21 \%)$. Short-term growth resilience, estimated for an extreme drought occurred after thinning (2005), yielded higher resilience for thinned stands, throughout improved resistance, but similar recovery than control. However, extreme droughts observed thereafter (for instance in 2012) do not support a long-term increase in resilience. Growth resilience, estimated for wetter-than-average years showed similar short-term enhanced resilience in thinned stand, while these differences dispelled afterward.
\end{abstract}

Keywords: dendrochronology; thinning; forest management; Abies pinsapo; recovery; resilience; resistance; BAI

\section{Introduction}

The Mediterranean basin entails a complex mosaic of near-to-natural ecosystems, characterized by strong seasonality that drives two periods of growth limitation (winter and summer). These limiting factors are even more relevant for relict species, such as Abies pinsapo, an endemic and threatened fir species from southern Spain and northern Morocco. Relict species have suffered long-term isolation that led to a morphological differentiation and usually genetic drift [1,2]. Several studies indicate that, since the 1970s, the frequency and intensity of drought periods increased, which have modified the hydrological cycle of the Mediterranean ecosystems and has led to a decline in productivity $[3,4]$. These studies also indicate that the relic forest ecosystems are among the most affected by ongoing climate change in the Mediterranean region, where climate 
models forecast an even greater increase in the concurrence, intensity and duration of drought events throughout the 21st century $[5,6]$.

In this situation, actions are required in order to apply management strategies that allow an improved adaptive capacity and higher survival rate of drought-sensitive trees. Among the different options discussed as suitable ecological applications to adaptive management, thinning for stand-canopy structural diversity enhancement has been recently investigated, providing several evidences about its mitigating role, reducing the sensitivity of some forests ecosystem to extreme drought events [7].

\section{Material and Methods}

This study was performed in 6 plots of Abies pinsapo forest located in Sierra de las Nieves Natural Park (Málaga, southern Spain, $36^{\circ} 44^{\prime} \mathrm{N} 4^{\circ} 59^{\prime} \mathrm{W}$. The area is characterized by a predominance of calcareous brown soils [8]. This Mediterranean fir is regularly subjected to water deficit from June to September. The annual mean temperature is about $11.6^{\circ} \mathrm{C}$, mean annual precipitation is about $1089 \mathrm{~mm}$. However, a decrease from 1900 to present of $108.94 \mathrm{~mm}$ in annual precipitation has been reported for the area, along with an increase of $1.63{ }^{\circ} \mathrm{C}$ in mean annual temperature. To carry out this study, data on precipitation and average temperature for drier- and wetter-than-average years in the 20th century have been obtained using regional gridded data from CRU TS 3.0 [9].

In order to quantify the effect of the different thinning treatments, we randomly selected 6 different plots in the area of study. To reduce confusion from environmental noise, all plots were located near to each other making sure that microclimatic and edaphic characters were similar [10]. Experimental thinning was designed and performed in October 2004, attempting to enhance stand structure diversity by (1) reducing tree competition, (2) increasing the equitability of size classes (i.e. diversity) and (3) randomizing tree spatial pattern [10]. We randomly selected three pairs of plots to which one of different thinning intensity treatments were applied: C, Control; T30\%, for a thinning of $30 \%$ of tree basal area removed; and T60\%, for a thinning of the $60 \%$. Using dendrochronological data obtained in 2019 from controls and the remaining trees whiting the thinned plots, we obtained basal area increment (BAI) time series [10]. BAI data were related to climate in order to identify drier- and wetter-than-average years. Then, three tree-growth response indices (Resistance, Rt; Recovery, Rc and Resilience, Rs) were calculated. These indices have been widely used to quantify forest growth responses to drought and wet periods [11,12]. The Resistance index (Rt) measures the capacity of the trees to absorb the effect of drought; this index is quantified by dividing the BAI in the extreme year and the mean of the 5 years before the extreme. The Recovery index (Rc) is quantified by dividing the mean BAI of the 5 years after the extreme year and the BAI in such extreme. The Resilience index (Rs) is the ratio between the mean BAI of the 5 years after the extreme and the mean BAI of the 5 years before [11-13].

\section{Results and Discussion}

To calculate the values of Rt, Rc and Rs, four of the driest years $(1983,1995,2005$, and 2012) and four of the wettest years $(1996,2000,2006$, and 2010) were studied to assess the short- and long-term effects of thinning.

Our dendrochronological data support a similar age and similar pre-thinning BAI values among plots (Table 1). However, post-thinning BAI values presented significant differences in growth between treatments, with increases of approximately $21.7 \%, 104.3 \%$ and $141.6 \%$ in the Control, $30 \%$ and $60 \%$ thinning-intensity treatments, respectively. These results support that stand-structure diversification and competition release by thinning may be an effective management for drought-sensitive forests, as other studies indicated, suggesting an increase in water uptake and growth $[7,10]$. 
Table 1. Values of mean tree age, pre- and post-thinning mean basal area increment (BAI pre, BAI post) and pre/post BAI $\%$ change for each treatment.

\begin{tabular}{ccccc}
\hline Treatment & AGE $\mathbf{( y r})$ & BAI Pre $\left(\mathbf{c m}^{2}\right)$ & BAI Post $\left(\mathbf{c m}^{2}\right)$ & \% Change \\
\hline Control & 58.2 & 3.16 & 3.85 & 21.76 \\
Thinning 30\% & 52.7 & 2.87 & 5.87 & 104.32 \\
Thinning $60 \%$ & 50.9 & 3.82 & 9.22 & 141.59 \\
\hline
\end{tabular}

Regarding the analysis of the short-term growth response in extreme years, both dry (2005) and wet (2006), we observed a significant increase in the Rt values, in both $30 \%$ and $60 \%$ thinning plots, compared to the Control plots (Figure 1). Rc was similar among treatments, and therefore, the improved Rt led to higher Rs in the thinned plots. Thereafter, successive drier- and wetter-than-average years (2012 and 2010 respectively) do not support this enhanced Rt, nor Rs in the thinned plots (Table 2, Figure 1). Our results suggest that thinning enhanced long-term BAI in the remaining trees within the thinned plots, as well as the short-term growth Rs, throughout improved Rt. However, enhanced long-term growth Rs to withstand extreme drought events was not observed.

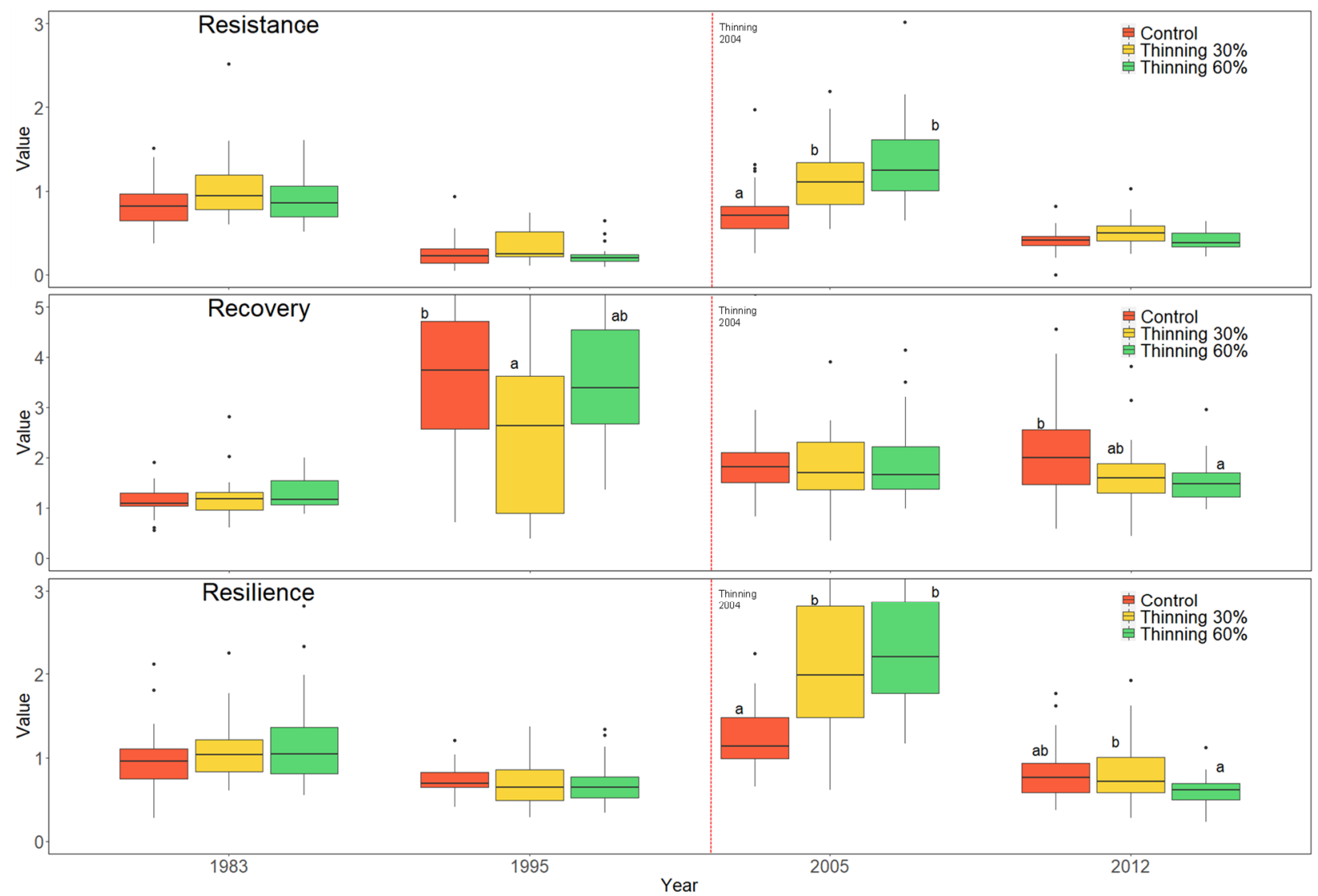




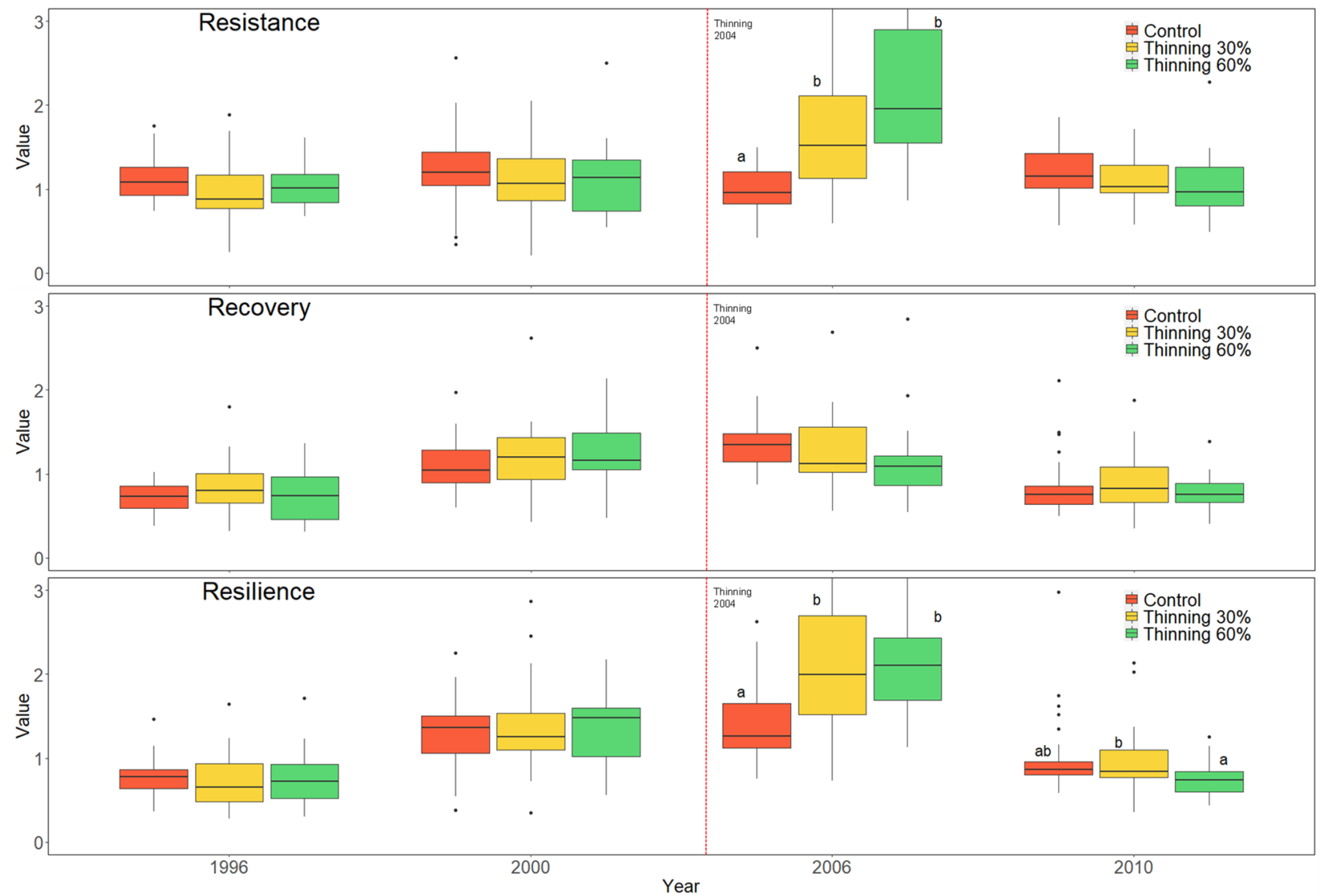

Figure 1. Mean values of tree-growth resistance, recovery and resilience for pre-thinning dry (1983, 1995) and wet (1996, $2000)$ years; and post-thinning dry $(2005,2012)$ and wet $(2006,2010)$ years. Vertical line indicates the thinning treatment (2004). Different letters indicate significant differences for ANOVA among Control (red), 30\% (yellow) and 60\% (green) thinning treatments for a given year.

Table 2. Percentage of variation of resistance, recovery and resilience for each treatment.

\begin{tabular}{cccccccc}
\hline \multicolumn{3}{c}{ \% of Variation after Treatment-Dry Years } & \multicolumn{3}{c}{$\%$ of Variation after Treatment-Wet Years } \\
\hline Plot & Control & Thinning $\mathbf{3 0} \%$ & Thinning $\mathbf{6 0} \%$ & Plot & Control & Thinning $\mathbf{3 0} \%$ & Thinning $\mathbf{6 0} \%$ \\
\hline Resistance & 7.13 & 46.89 & 46.91 & Resistance & -3.52 & 55.53 & 50.27 \\
Recovery & -30.72 & 0.32 & -38.67 & Recovery & 25.17 & 0.85 & -2.78 \\
Resilience & 22.21 & 97.93 & -31.59 & Resilience & 13.78 & 74.05 & 49.30 \\
\hline
\end{tabular}

Author Contributions: Conceptualization, J.A.C., J.C.L. and R.S.-S.; Funding acquisition, J.A.C., J.C.L. and R.S.-S.; Investigation, J.A.C., J.C.L., R.S.-S., P.C.-G., V.L., B.V. and J.I.S.G.; Methodology, R.S.-S. and P.C.-G.; Software, P.C.-G., J.C.L. and R.S.-S.; Writing-original draft, P.C.-G.; Writing, review and editing, J.A.C., J.C.L., R.S.-S., P.C.-G., V.L., B.V. and J.I.S.G. All authors have read and agreed to the published version of the manuscript.

Funding: This research was financially supported by the project LESENS (RTI2018-096884-B-C33) from the Spanish Ministry of Science, Innovation, and Universities and by the VULBOS project (UPO-1263216) from the ERDF funds of the Andalusian regional government 2014-2020. P.C.-G. was funded by the Environmental predoctoral grant by the Fundación Tatiana Pérez de Gúzman El Bueno 2018. This research was supported by the research groups RNM-296 "Ecología Forestal y Dinámica del Paisaje" and RNM-313 "Estructura y Función de Ecosistemas Mediterráneos".

Conflicts of Interest: The authors declare no conflict of interest. The funders had no role in the design of the study; in the collection, analyses, or interpretation of data; in the writing of the manuscript, or in the decision to publish the results. 


\section{References}

1. Alba-Sánchez, F.; López-Sáez, J.A.; Benito de Pando, B.; Linares, J.C.; Nieto-Lugilde, D.; López-Merino, L. Past and present potential distribution of the Iberian Abies species: A phytogeographic approach using fossil pollen data and species distribution models. Divers. Distrib. 2010, 16, 214-228.

2. Linares, J.C.; Camarero, J.J.; Carreira, J.A. Plastic responses of Abies pinsapo xylogenesis to drought and competition. Tree Physiol. 2009, 29, 1525-1536.

3. de Luis, M.; Novak, K.; Raventós, J.; Gričar, J.; Prislan, P.; Čufar, K. Climate factors promoting intra-annual density fluctuations in Aleppo pine (Pinus halepensis) from semiarid sites. Dendrochronologia 2011, 29, 163-169.

4. de Luis, M.; Čufar, K.; Di Filippo, A.; Novak, K.; Papadopoulos, A.; Piovesan, G.; Rathgeber, C.B.K.; Raventós, J.; Saz, M.A.; Smith, K.T. Plasticity in Dendroclimatic Response across the Distribution Range of Aleppo Pine (Pinus halepensis). PLoS ONE 2013, 8, e83550.

5. Tejedor, E.; Saz, M.A.; Esper, J.; Cuadrat, J.M.; de Luis, M. Summer drought reconstruction in northeastern Spain inferred from a tree ring latewood network since 1734. Geophys. Res. Lett. 2017, 44, 8492-8500.

6. Vicente-Serrano, S.M.; López-Moreno, J.I.; Drumond, A.; Gimeno, L.; Nieto, R.; Morán-Tejeda, E.; Lorenzo-Lacruz, J.; Beguería, S.; Zabalza, J. Effects of warming processes on droughts and water resources in the NW Iberian Peninsula (1930-2006). Clim. Res. 2011, 48, 203-212.

7. Gavinet, J.; Ourcival, J.; Limousin, J. Rainfall exclusion and thinning can alter the relationships between forest functioning and drought. New Phytol. 2019, 223, 1267-1279.

8. Navarro-Cerrillo, R.M.; Camarero, J.J.; Manzanedo, R.D.; Sánchez-Cuesta, R.; Quintanilla, J.L.; Salguero, R.S. Regeneration of Abies pinsapo within gaps created by Heterobasidion annosuminduced tree mortality in southern Spain. IForest 2014, 7, 209215.

9. University of East Anglia Climate Research Unit (CRU). CRU. 2008. Available online: http://climexp.knmi.nl/start.cgi?id=someone@somewhere (accessed on 16 March 2018).

10. Lechuga, V.; Carraro, V.; Viñegla, B.; Carreira, J.A.; Linares, J.C. Managing drought-sensitive forests under global change. Low competition enhances long-term growth and water uptake in Abies pinsapo. For. Ecol. Manag. 2017, 406, 72-82.

11. Gazol, A.; Camarero, J.J.; Vicente-Serrano, S.M.; Sánchez-Salguero, R.; Gutiérrez, E.; de Luis, M.; Sangüesa-Barreda, G.; Novak, K.; Rozas, V.; Tíscar, P.A.; et al. Forest resilience to drought varies across biomes. Glob. Chang. Biol. 2018, 24, $2143-2158$.

12. Gazol, A.; Ribas, M.; Gutiérrez, E.; Camarero, J.J. Aleppo pine forests from across Spain show drought-induced growth decline and partial recovery. Agric. For. Meteorol. 2017, 232, 186-194.

13. Serra-Maluquer, X.; Mencuccini, M.; Martínez-Vilalta, J. Changes in tree resistance, recovery and resilience across three successive extreme droughts in the northeast Iberian Peninsula. Oecologia 2018, 187, 343-354. 